\title{
EDITORIAL
}

\section{Five years on....and four challenges for the pharmaceutical industry}

\author{
The fifth anniversary of the journal sees its original mission — to provide information and \\ insight to help tackle dwindling RED productivity — as relevant as ever. What challenges \\ does the industry face over the next 5 years and how could it conquer them?
}

"Despite all the excitement that accompanies each wave of technical innovation, from protein structure determination to proteomics, and from combinatorial chemistry to e-clinical trials, the fundamental truth is that pharmaceutical companies are not producing drugs any faster than they were before these innovations came along." In January 2002, these words appeared in the editorial that launched Nature Reviews Drug Discovery.

Five years and over 5,000 pages of articles later, the obvious question is whether drug discovery and development is in a healthier state than when the journal started. Regular readers of the journal will already know the answer to this question: a resounding no. The number of new molecular entities approved each year still remains at disappointingly low levels, and the industry has been wounded by several issues such as drug safety and patent expiries of top-selling drugs. So, the question posed at the beginning of our first editorial is relevant enough to be repeated in this one: "Were expectations too high, or is there something fundamentally wrong?"

There have been many reasons given for the current dip in $R \& D$ productivity, from the type of targets being pursued to the tools being used to develop drug candidates, and yet there seems to be no simple solution. Perhaps a viewpoint from beyond the industry could help. The four greatest challenges that businesses in general face over the next 5 years was the subject of a recent talk by Thomas Stewart, editor of the Harvard Business Review, at an online information conference in London last November, and indeed, all four challenges are germane to the current state of drug discovery and development.

The first challenge is speed. From combinatorial chemistry to genomics, new concepts or technologies that claim to help accelerate drug development have arguably been too rapidly embraced without true validation. And in other areas of drug development, issues such as terminating unpromising compounds in development might not be being dealt with fast enough. At least part of the solution to both issues relies on appreciating that innovation and effective decision-making springs less from technologies and more from placing scientists in a stimulating environment, and providing them with the platform to explore all hypotheses and results.

Second is customer power. Rightly or wrongly, the image of an industry that takes innovative research from academic institutions and profits from it is one that currently resonates strongly with the public. Anyone in the field knows that drug discovery and development is a complex process, and that bringing a novel drug to market involves many years of multidisciplinary research, not to mention a certain amount of luck. Pfizer's decision to terminate the development of torcetrapib for safety reasons (see page 14 of this issue) is a timely reminder of the risks taken in developing drugs, and this message needs to be communicated more effectively outside the industry.

Low-cost competition is the third challenge. The industry is going through an unprecedented period of patent expiries - an estimated US $\$ 16$ billion of revenues on marketed products is expected to be lost to patent expiries this year - without the late-stage pipeline to compensate. Generics companies have become more aggressive in their tactics, and biopharma companies are only beginning to show signs that they are responding (see page 6 in this issue). Maintaining growth in this climate will be a top priority for companies over the next 5 years, and the other aspect of low-cost 'competition' - outsourcing $\mathrm{R} \& \mathrm{D}$ - could prove an increasingly popular strategy.

The last of the challenges - decision-making under uncertainty and management without supervision - is particularly pertinent to drug discovery, not just because of the inherent uncertainty in innovative drug $R \& D$, but also because of the key influence of the changing regulatory environment on the process. But in the 5 years since the launch of the journal, the FDA has had a permanent commissioner for less than half of the time, making dealing swiftly with important issues and planning for the future highly challenging. At least now, with the Senate confirmation of Andrew von Eschenbach as permanent commissioner in December (see page 14 of this issue) an important step forward has been made, not only for the agency, but also for the industry as a whole, in tackling the challenges of the next 5 years. 